\title{
The Adverse Events in Lumbar Dynamic Stabilization: a Prospective Case Series
}

\author{
Pedro Gregori', Melissa Manfrinato Avamileno1,2, \\ Henrique Isoldi Pohl' ${ }^{2}$, Alexandre Barros Costa ${ }^{2}$, \\ Marcelo Wajchenberg ${ }^{3}$, Luiz Carlos de Abreu', \\ Blanca Elena Guerrero Daboin ${ }^{1}$, Marcelo Ferraz de Campos ${ }^{1}$, \\ Vitor Engrácia Valenti ${ }^{1}$, Luciano Miller Reis Rodrigues ${ }^{1,2}$
}

\section{Abstract}

Background: We aimed to evaluate the complication rate in lumbar dynamic stabilization surgery of back pain in situations where conventional rigid implants could have been employed, with a follow-up of at least five years.

Methods and Findings: Prospective study. There were included, all patients who underwent semi-rigid fixation of lumbar spine with the dynamic system during the period 2004 to 2010 in our department. Adverse events and reoperations were registered for analysis. In the study period, 144 patients were treated with the dynamic system and all of them were studied. Three screws were badly positioned. There were two (1.39\%) infections, with need of surgical cleaning in one case. Out of 770 screws, the late complications included a radiolucency signal in 22 screws (2.86\%) and four broken screws $(0.52 \%)$. Nineteen patients (20.13\%) needed reoperation due to pain or screw associated problems. Three (2.08\%) of those cases received additional treatment due to segmental kyphosis, five (3.47\%) due to flat back, five $(3.47 \%)$ due to adjacent level stenosis, four (2.7\%) due to lumbar pain complaints, and two (1.39\%) due to a broken screw.

Conclusions: The lumbar dynamic stabilization system is a fusion option for the treatment of degenerative spinal diseases. However it is not free of adverse events, the rates of implant failures, complications, and reoperations found in this study are similar to those described in the published literature about rigid systems.
1 Laboratório de Delieneamento de Estudos e Escrita Científica. Disciplina de Metodologia da Pesquisa. Departamento de saúde da Coletividade. Faculdade de Medicina do ABC. Santo André, SP, Brazil.

2 Disciplina de Ortopedia e Traumatologia. Faculdade de Medicina do ABC. Santo André, SP, Brazil.

3 Grupo de Cirurgia de Coluna. Hospital São Paulo. Escola Paulista de Medicina. Universidade Federal de São Paulo (Unifesp), São Paulo, Brazil.

Contact information:

Luciano Miller Reis Rodrigues.

Address: Rua Tucuma, 199 - apto 141. São Paulo (SP) - Brazil. Cep: 01455-050 Tel: (55 11) 3815-9996.

झ luciano.miller@uol.com.br

Keywords

Lumbar vertebrae; Surgery; Spinal fusion; Low Back Pain. 


\section{Introduction}

Low back pain (LBP) is a common clinical problem with a major socioeconomic impact [1]. Lifetime incidence of low back pain is estimated to be $70-80 \%$. Consequently, the number of surgeries performed for low back pain is increasing. Recent advances in fusion techniques have elevated the rates of arthrodesis procedures without an equivalent improvement in pain relief [2]. Lumbar fusion surgery is the procedure of choice for various spinal diseases. However this procedure is not devoid of risks and complications. Many complications may occur, including pseudoarthrosis, infection, pain at the graft removal site, and junction syndrome [3].

The definition of instability remains as a matter of debate, and it may refer to symptoms of low back pain exacerbated by movement and associated with intersegmental movements that are abnormal or excessive (laxity) at one or more spinal levels. Abnormal movements can involve angular rotations between vertebrae, or "translation" movements in which the vertebrae move past each other at the same orientation, such as in an anterior slip of $\mathrm{L} 5$ relative to the sacrum. This situation comprises patients whose spines may need load rebalancing through fusion and a better load sharing with the use of alternative dynamic systems [4-6].

There is a trend on the study and development of motion preservation techniques to avoid fusionrelated complications, such as the adjacent disc degeneration. The dynamic stabilization theoretical means of alleviating lumbar pain is by improving load transfer mechanisms through the spinal column. Dynamic posterior stabilization systems permit restricted, controlled motion across a functional spinal unit $[7,8]$. These systems may assist the progressive and chronic natural ageing of the spine, while avoiding the acute installation of rigidity in the spine unit. It is important to remember that the human spine reacts quite well to slow progressive modifications, however, often, it does not accept abrupt, acute modifications. The lumbar spine may behave likewise. The dynamic systems are designed to preserve and improve intersegmental kinematics and reduce load onto the facet joint and the intervertebral disc [9]. Biomechanical tests of dynamic systems have been published elsewhere and they are not the subject of this text.

In 1991, Dubois et al. [10] began their researches on a dynamic stabilization system for spine surgery, and the first implant was used in France in 1994. The principle behind the implant design was the rebalancing of load transmission through the spine. The purpose of the device is to restore segmental stiffness close to the normal mobility. Its principle of action is to tighten the posterior ligament elements and posterior disc annulus, to tighten joint capsules, repositioning the articular processes in the anatomical function, while limiting flexion and extension to remove the unwanted movements that may generate the abnormal phenomena that compress neural structures. The ideal situation would be to allow some degree of freedom to minimize stress to adjacent levels of the stabilization and particularly on the level above, junctional to the fixation [11]. The system utilizes the same technique of strategically placing screws as the conventional fusion technique. To date, a significant number of studies have examined the clinical outcome of patients who underwent stabilization with the Dynesis implant [12-14]. However, there are a limited number of articles focused on the adverse events over time, comparing the results of fusion.

The main objective of this study is to evaluate the adverse effects of the dynamic stabilization system in situations where conventional rigid implants could have been employed with a follow-up of at least five years.

\section{Methods}

This prospective study included all patients who underwent semi-rigid lumbar spine fixation with 
the dynamic system (Dynesys System) consecutively between 2004 and 2010. Three surgeons operated all patients using the same technique. Conservative treatments for pain with medication, physiotherapy, and infiltrations for a minimum of six months were carried out before surgery. Criteria for exclusion were patients with history of a previous surgery, trauma, body mass index $(\mathrm{BMl})>35 \mathrm{~kg} / \mathrm{m}^{2}$, patients with osteoporosis or cancer.

The patient was positioned in ventral decubitus, with attention observed to maintain lumbar lordosis. The surgery was performed through a midline lumbar approach when there was a need for canal decompression and through posterolateral acess when decompression was not necessary. After completed neural decompression, pedicle screws were inserted under radioscopic control using a C-arm. The screws were convergent and parallel to the upper vertebral plateau. The polycarbonate urethane spacer of Dynesys was cut according to the measured distance between the screws, and the length was chosen to balance for any existing lordosis or kyphosis. In cases of degenerative disc disease (Pfirrmann grade greater than 3), disc space distraction was performed. The central cord and the spacer were then locked within the screw heads. A soft brace was administered after surgery for eight weeks.

The follow up had a minimum of 4 years and a maximum of 10 years, the presence of adverse events and the incidence of reoperations were observed and registered for analysis. It was conducted descriptive statistical analysis in which the variables were presented by absolute and relative frequency.

\section{Results}

During the study period, 144 patients were treated with the dynamic system and included in the study. The treated diseases in the sample comprised lumbar degenerative disc disease in 49 patients with untreatable low back pain, 35 spinal canal stenosis, 40 disc herniations and 20 spondylolisthesis. There were 70 women and 74 men, with an average age of 46 years. The L4-L5 level was the most commonly treated. In the study, the instrumentation was associated with decompression in 95 patients (Table 1).

Table 1. Descriptive analysis of patients submitted to dynamic surgery of spinal pain.

\begin{tabular}{|c|c|c|}
\hline Variable & $\mathrm{n}$ & $\%$ \\
\hline \multicolumn{3}{|l|}{ Sex } \\
\hline Male & 74 & 51.4 \\
\hline Female & 70 & 48.8 \\
\hline \multicolumn{3}{|l|}{ Disease } \\
\hline Degenerative disc disease & 68 & 47.2 \\
\hline Hernia & 41 & 28.5 \\
\hline Stenosis & 19 & 13.2 \\
\hline Spondylolisthesis & 16 & 11.1 \\
\hline \multicolumn{3}{|l|}{ Number of levels involved } \\
\hline One & 55 & 38.2 \\
\hline Two & 70 & 48.6 \\
\hline Three & 18 & 12.5 \\
\hline Four & 1 & 0.7 \\
\hline \multicolumn{3}{|l|}{ Type of levels } \\
\hline L4L5-L5S1 & 66 & 45.8 \\
\hline L3L4-L5S1 & 2 & 1.4 \\
\hline L5S1 & 22 & 15.3 \\
\hline L3L4-L4L5-L5S1 & 14 & 9.7 \\
\hline L4L5 & 31 & 21.5 \\
\hline Others* & 9 & 6.3 \\
\hline \multicolumn{3}{|l|}{ Access } \\
\hline Medial & 96 & 66.7 \\
\hline Lateral & 48 & 33.3 \\
\hline \multicolumn{3}{|l|}{ Decompression } \\
\hline Yes & 96 & 66.7 \\
\hline No & 48 & 33.3 \\
\hline
\end{tabular}


Complications associated with screws included a radiolucency signal in 74 screws $(9.61 \%)$, four broken screws (0.52\%) and 7 bad positioned screws out of 770 screws (Table 2).

Out of total of patients, flat back occurred in nine of them $(6.25 \%)$, four cases with two levels of fixation, four cases with three levels and one case with four levels. In one patient $(0,69 \%)$, the screw was laterally dislocated during the follow-up period with a rupture of the cortical and lateral wall of the vertebral body. Intertransverse process arthrodesis was performed in one patient (0.69\%). Segmental kyphosis occurred in five patients (3.47\%), two cases with two levels of fixation and two with three levels. Seven patients presented stenosis in the adjacent spinal level (4.68\%; Table 3).

Table 2. Distribution of the number of screws with complications by type and the variables disease, number of levels involved and access.

\begin{tabular}{|c|c|c|c|c|c|c|}
\hline \multirow{3}{*}{ Variables } & \multicolumn{6}{|c|}{ Type of complication } \\
\hline & \multicolumn{2}{|c|}{ Radioluscency signal } & \multicolumn{2}{|c|}{ Positioned badly } & \multicolumn{2}{|c|}{ Breaks } \\
\hline & $n$ & $\%$ & $n$ & $\%$ & $n$ & $\%$ \\
\hline \multicolumn{7}{|l|}{ Disease } \\
\hline Degenerative disc disease & 8 & 57.1 & 4 & 28.6 & 2 & 14.3 \\
\hline Herniation & 12 & 80 & 3 & 20 & - & - \\
\hline Stenosis & 28 & 100 & - & - & - & - \\
\hline Spondylolisthesis & 26 & 92.9 & - & - & 2 & 7.1 \\
\hline \multicolumn{7}{|l|}{ Number of levels involved } \\
\hline One & 28 & 82.4 & 3 & 8.8 & 3 & 8.8 \\
\hline Two & 25 & 83.3 & 4 & 13.4 & 1 & 3.3 \\
\hline Three & 19 & 100 & - & - & - & - \\
\hline Four & 2 & 100 & - & - & - & - \\
\hline \multicolumn{7}{|l|}{ Access } \\
\hline Medial & 30 & 85.7 & 1 & 2.9 & 4 & 11.4 \\
\hline Lateral & 44 & 88 & 6 & 12 & - & - \\
\hline
\end{tabular}

Table 3. Distribution of patients who had complication during the follow-up period of five years by different causes and the variables disease and number of levels involved

\begin{tabular}{|c|c|c|c|c|c|c|c|c|c|c|}
\hline \multirow{3}{*}{ Variables } & \multicolumn{10}{|c|}{ Causes } \\
\hline & \multicolumn{2}{|c|}{$\begin{array}{l}\text { Segmental } \\
\text { kyphosis }\end{array}$} & \multicolumn{2}{|c|}{ Flat back } & \multicolumn{2}{|c|}{$\begin{array}{l}\text { Adjacent level } \\
\text { stenosis }\end{array}$} & \multicolumn{2}{|c|}{$\begin{array}{c}\text { Lumbar back } \\
\text { pain }\end{array}$} & \multicolumn{2}{|c|}{ Broken screw } \\
\hline & $n$ & $\%$ & $\mathrm{n}$ & $\%$ & $\mathrm{n}$ & $\%$ & $\mathrm{n}$ & $\%$ & $\mathrm{n}$ & $\%$ \\
\hline \multicolumn{11}{|l|}{ Disease } \\
\hline Degenerative disc disease & 2 & 9.5 & 5 & 24 & 1 & 4.7 & 12 & 57 & 1 & 4.7 \\
\hline Hernia & 1 & 33.3 & - & - & 2 & 66.7 & - & - & - & - \\
\hline Stenosis & 2 & 18 & 3 & 27 & 4 & 37 & 2 & 18 & - & - \\
\hline Spondylolisthesis & - & - & 1 & 17 & - & 66 & 4 & - & 1 & 17 \\
\hline Total of patients & 5 & & 9 & & 7 & & 18 & & 2 & \\
\hline \multicolumn{11}{|l|}{ Number of levels involved } \\
\hline One & 1 & 10 & - & - & 2 & 20 & 6 & 60 & 1 & 10 \\
\hline Two & 2 & 10 & 4 & 20 & 3 & 15 & 10 & 50 & 1 & 5 \\
\hline Three & 2 & 20 & 4 & 40 & 2 & 20 & 2 & 20 & - & - \\
\hline Four & - & - & 1 & 100 & - & - & - & - & - & - \\
\hline
\end{tabular}


Among the patients with adverse events, there were 3 cases of disc herniation, 20 cases of degenerative disc disease, 5 cases of spondylolisthesis and spinal stenosis in 11 patients.

A total of 19 patients (13.19\%) needed reoperation due to pain or screw-related problems. Three $(2.08 \%)$ of those 19 cases received additional treatment due to segmental kyphosis, 5 cases (3.47\%) due to flat back, 5 cases $(3.47 \%)$ due to adjacent level stenosis, 4 cases $(2.7 \%)$ due to lumbar pain complaints, and 2 cases (1.39\%) due to a broken screw (Table 4).

Table4. Distribution of patients by different causes of reoperation.

\begin{tabular}{|l|c|c|}
\hline \multicolumn{1}{|c|}{ Variable } & $\mathbf{n}$ & \% \\
\hline Segmental kyphosis & 3 & 2.1 \\
\hline Flat back & 5 & 3.5 \\
\hline Adjacent stenosis & 5 & 3.5 \\
\hline Back pain only & 4 & 2.6 \\
\hline Broken screw & 2 & 1.3 \\
\hline No need of reoperation & 125 & 86.7 \\
\hline \multicolumn{1}{|c|}{ Total } & 144 & 100 \\
\hline
\end{tabular}

\section{Discussion}

Lumbar fusion has been the treatment of choice for low back pain due to different spine diseases, with associated instability, after failed conservative treatment. However, there is no clear association between fusion and clinical improvement $[15,16]$. Martin et al. [17] demonstrated in their study that patients who underwent fusion have a higher percentage of reoperation compared with the only neural decompression group. The dynamic neutralization system has been developed in an attempt to avoid complications associated with fusion in patients requiring fixation, and has become an option for the treatment of degenerative lumbar spine diseases. The system was developed to avoid adjacent spinal level overload, a possible event suggested to occur after rigid fusion. This procedure, however, is not free of complications. In our study, we implanted dynamic stabilization in cases where fusion has been traditionally used as first choice procedure.

Cheh et al. [18] demonstrated that more complications happened when more levels were stabilized. Our data also depicted that in surgeries comprising two or more levels, there was a higher incidence of disease in the adjacent level, with higher number of complications.

Beastall et al. [19] used magnetic resonance imaging to evaluate the range of motion after fixation with the dynamic implant. The study suggested a decrease in height in the anterior portion of the disc compared to the posterior portion and, therefore, a trend to reduce lumbar lordosis using this system. However, the procedure did not obtain a significant lordosis reduction in a neutral posture and no significant impact was noted on the inclination of the operated or adjacent segments. In our study, we noticed a loss of lumbar lordosis in seven patients (4.86\%), with five cases undergoing multilevel surgery. It became clear that the number of treated levels influenced negatively the lumbar lordosis

The benefit of the dynamic system is the promotion of stability without fusion. Several publications have also demonstrated that patients who develop pseudoarthrosis with pedicle screw fixation presented clinical results similar to the results from patients with lumbar fusion [20-23]. However, this study has shown a considerable frequency of adverse events in all categories of spine disease. There were $10.1 \%$ screw loosening with the dynamic stabilization system and similar results were published by Stoll et al. [24]. Grob et al. [13] demonstrate that the dynamic stabilization without decompression had a significantly less favorable outcome compared to the group where associated decompression was performed. There are multiple variables during the surgery which could have led 
to screw loosing such as: screw repositioning during the procedure, a lack of screw medialization, inappropriate screw diameter. The spinal level that was treated probably influenced screw failure too because half of the failures occurred at the S1 level. Patients with screw loosening were asymptomatic and in several cases there was osseous integration on later follow-up.

During patient follow-up, we had 19 patients (13.19\%) who underwent reoperation. Kuntz et al. [25], in 10 years of monitoring, reported a $2.3 \%$ reoperation rate per year in their study. Booth et al. [26] showed a $12 \%$ revision rate due to transitional syndrome over a five-year follow-up period. Long term in vitro stress generated insignificant plastic deformation of the cord by $1.2 \%$ and of the spacer by $6.5 \%$ after 5 million distraction-compression cycles [9]. In our reoperation cases, we did not observe implant deformation following spacer removal, even though we performed rotation movements of the trunk which could increase the chance of implant fatigue.

With these results we believe that two factors were responsible for the high incidence of adverse effects in our series. The first is a screw interface with bone where there is a great number of screws radiolucency. The second was the loss of lordosis after fixation with a dynamic screw in patients with more than one level of fixation, since one level of dynamic stabilization had little incidence of adverse effects. Thus, Fiusa [27] identify stabilometric changes before and after a program of proprioceptive training the short time, with oneleg proprioceptive training has been shown to be effective for improving balance by reducing body sway. Health care is conventionally regarded as the diagnosis, treatment, and prevention of disease, illness, injury, and other physical and mental impairments in humans. How we defie the quality of public health at any given time must be compatible with future generations enjoying health in an equivalent way $[28,29]$. More prospective and comparative studies are necessary to critically review the use of dynamic stabilization systems.

\section{Conclusion}

The lumbar dynamic stabilization system is an option for the treatment of degenerative spinal diseases. However it is not free of adverse events, the rates of implant failures, complications, and reoperations found in this study are similar to those described in the published literature about rigid systems.

\section{References}

1. Andersson GB. Epidemiological features of chronic low-back pain. Lancet 1999; 354(4): 581-5.

2. Boos N, Webb JK. Pedicle screw fixation in spinal disorders: a European view. Eur Spine J 1997; 6: 2-18.

3. Throckmorton TW, Hilibrand AS, Mencio GA. The impact of adjacent level disc degeneration on health status outcomes following lumbar fusion. Spine (Phila Pa 1976) 2003; 28: 254650.

4. Sato $H$, Kikuchi $S$. The natural history of radiographic instability of the lumbar spine. Spine (Phila Pa 1976)1993; 18: 2075-9.

5. Dupuis PR, Yong-Hing K, Cassidy JD. Radiologic diagnosis of degenerative lumbar spinal instability. Spine (Phila Pa 1976)1985; 10: 262-76.

6. Pitkänen $\mathrm{M}$, Manninen $\mathrm{H}$. Sidebending versus flexion-extension radiographs in lumbar spinal instability. Clin Radiol 1994; 49: 109-14.

7. Welch WC, Cheng BC, Awad TE. Clinical outcomes of the Dynesys dynamic neutralization system: 1-year preliminary results. Neurosurg Focus 2007; 22: E8.

8. Mulholland RC, Sengupta DK. Rationale, principles and experimental evaluation of the concept of soft stabilization Eur Spine J 2002; 11Suppl 2: S198-205.

9. Niosi CA, Zhu QA, Wilson DC. Biomechanical characterization of the three-dimensional kinematic behaviour of the Dynesys dynamic stabilization system: an in vitro study. Eur Spine J 2006; 15: $913-22$.

10. Dubois B, De Germay B, Schaerer NS, et al. Dynamic neutralization: a new concept for restabilization of the spine. In: Szpalski M, Gunzburg R, Pope MH (ed) Lumbar segmental instability. Philadelphia: Lippincott Williams and Wilkins; 1999. p 233-40.

11. Schmoelz W, Hubert JF, Nydegger T. Dynamic stabilization of the lumbar spine and its effects on adjacent segments: an in vitro experiment. J Spinal Disord Tech 2003; 16: 418-23. 
12. Bordes-Monmeneu M, Bordes-Garcia V, Rodrigo-Baeza F. Sistema de neutralización dinámica en la coluna lumbar. SISTEMA DYNESYS. Experiencia en 94 casos [System of dynamic neutralization in the lumbar spine: experience on 94 cases]. Neurocirugia (Astur) 2005; 16: 499-506.

13. Grob D, Benini A, Junge A. Clinical experience with Dynesys semirigid fixation system for the lumbar spine: surgical and patient-oriented outcome in 50 cases after an average of 2 years. Spine (Phila Pa 1976)2005; 30: 324-31.

14. Schnake KJ, Schaeren S, Jeanneret B. Dynamic stabilization in addition to decompression for lumbar spinal stenosis with degenerative spondylolisthesis. Spine (Phila Pa 1976) 2006; 31: 442-9.

15. Turner JA, Ersek M, Herron L. Patient outcomes after lumbar spinal fusions. JAMA 1992; 268: 907-11.

16. Robaina-Padrón FJ. Controversias de la cirugía instrumentada y el tratamiento del dolor lumbar por enfermedad degenerativa. Resultados de la evidencia científica [Controversies about instrumented surgery and pain relief in degenerative lumbar spine pain. Results of scientific evidence]. Neurocirugia 2007; (Astur) 18: 406-13.

17. Martin BI, Mirza SK, Comstock BA. Reoperation rates following lumbar spine surgery and the influence of spinal fusion procedures. Spine (Phila Pa 1976)2007; 32: 382-7.

18. Cheh G, Bridwell KH, Lenke LG. Adjacent segment disease followinglumbar/thoracolumbar fusion with pedicle screw instrumentation: a minimum 5-year follow-up. Spine (Phila Pa 1976) 2007; 32: 2253-7.

19. Beastall J, Karadimas E, Siddiqui M. The Dynesys lumbar spinal stabilization system: a preliminary report on positional magnetic resonance imaging findings. Spine (Phila Pa 1976) 2007; 32: 685-90.

20. Agazzi S, Reverdin A, May D. Posterior lumbar interbody fusion with cages: an independent review of 71 cases. J Neurosurg 1999; 91(2 Suppl): 186-92.

21. Fritzell $P$, Hägg $O$, Wessberg P. Chronic low back pain and fusion: a comparison of three surgical techniques: a prospective multicenter randomised study from the Swedish lumbar spine study group. Spine (Phila Pa 1976)2002; 27: 1131-41.

22. Andersen T, Christensen FB, Hansen ES. Pain 5 years after instrumented and non-instrumented posterolateral lumbar spinal fusion. Eur Spine J 2003; 12: 393-9.

23. France JC, Yaszemski MJ, Lauerman WC. A randomized prospective study of posterolateral lumbar fusion. Outcomes with and without pedicle screw instrumentation. Spine (Phila Pa 1976) 1999; 24: 553-60.

24. Stoll TM, Dubois G, Schwarsenbach O. The dynamic neutralization system for the spine: a multi-center study of a novel non-fusion system. Eur Spine J 2002; 11 Suppl 2: S170178.
25. Kuntz KM, Snider RK, Weinstein JN. Cost-effectiveness of fusion with and whithout instrumentation for patients with degenerative spondylolisthesis and spinal stenosis. Spine (Phila Pa 1976) 2000; 25: 1132-1139.

26. Booth KC, Bridwell KH, Eisenberg BA. Minimum 5-years results of degenerative spondylolisthesis treated with decompression and instrumented posterior fusion. Spine (Phila Pa 1976) 1999; 24: 1721-1727.

27. Fiusa JM, Fréz AR, Pereira, WM. Analysis after stabilometric proprioceptive exercises: a randomized controlled clinical study. Journal of Human Growth and Development. 25(1): 63-67. DOI: http://dx.doi.org/10.7322/jhgd.96769

28. trash HK, Carpentier R. The evolving role of public health in the delivery of health care. Journal of Human Growth and Development, 2012; 22(3): 396-399.

29. Torriani-Pasin, G.M. Bonuzzi, M.A. Soares, G.L. Antunes, G.C. Palma, C.B. Monteiro, L.C. de Abreu, V.E. Valenti, A.P. Junior, R. Wajnsztejn, U.C. Correa, Performance of Down syndrome subjects during a coincident timing task, Int Arch Med, 6 (2013) 6-15.

\section{Comment on this article:}

\section{(f) B in $8+\mathbf{S} P$}

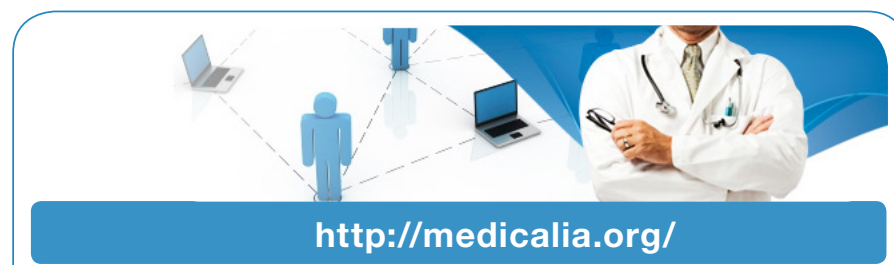

Where Doctors exchange clinical experiences, review their cases and share clinical knowledge. You can also access lots of medical publications for free. Join Now!

\section{Publish with iMedPub}

http://www.imed.pub

International Archives of Medicine is an open access journal publishing articles encompassing all aspects of medical science and clinical practice. IAM is considered a megajournal with independent sections on all areas of medicine. IAM is a really international journal with authors and board members from all around the world. The journal is widely indexed and classified Q1 in category Medicine. 